\title{
Incidence of Inborn Errors of Metabolism in Sick Neonates in a Tertiary Care Hospital in Developing Country
}

\section{Mizanur Rahman', Kanij Fatema ${ }^{1 *}$ and Shahidullah ${ }^{2}$}

\author{
${ }^{1}$ Department of Pediatric Neurology, BSMMU, Dhaka, Bangladesh
}

${ }^{2}$ Department of Neonatology, BSMMU, Dhaka, Bangladesh

\section{Introduction}

The term "inborn errors of metabolism" (IEM), also referred to as congenital metabolic diseases, is described as the hereditary deficiency of enzymes or alteration in protein structure and function resulting in metabolic derangement that may have pathologic consequences [1]. These disorders result in substrate accumulation causing minor to severe neurological and psychiatric manifestations resulting in lifelong disability or death [2].

The incidence of IEM collectively is estimated to be as high as 1 in 800 live births, but it varies greatly [3]. There are limited published studies on newborn screening of IEM in developing countries. The World Health Organization (WHO) estimated amino acid disorders to account for approximately $10 \%$ of profoundly retarded children [4]. In one study done in India the prevalence of IEM was 1 per 1000 newborns [5]. Screening of mentally retarded children in India revealed that $0.5 \%$ to $2.4 \%$ of children had amino acid disorders [6].

Detection of neurometabolic disorders is hampered by delay in early recognition of common phenotypes. The clinical features resemble illnesses like sepsis, seizures and so forth. Lack of specificity of presenting clinical symptoms in these inherited metabolic diseases necessitates a large number of subjects to be studied by biochemical tests. Tests particularly useful in detecting and classifying neurometabolic disorders include blood gases, blood ammonia, urinary ketones and blood lactate. Amino acid and acylcarnitine analysis of newborn dried blood spots using tandem mass spectrometry (TMS/MS) [7] is rapidly gaining worldwide support as the method of choice for the screening metabolic disorders. Numerous reports in the literature describe the utility of MS/ MS for screening for amino, $[8,9]$ organic and fatty acid disorders or screening for combinations of the latter two.
Early diagnosis and treatment can reduce the morbidity and mortality associated with these diseases.

There are limited published studies on newborn IEM screening in Bangladesh. This study presents our experience on screening for neurometabolic disorders in sick newborns by simple metabolic screening.

\section{Material and Method}

This was a cross sectional study conducted to observe the incidence of inborn errors of metabolism in sick newborns in neonatal department of a tertiary care hospital in Bangladesh. It was conducted from January to December 2011. Average 15-20 neonates attend in the neonatal center every day in the center, out of them 4-5 neonates required admission. A total of 50 sick newborns clinically suspected for inborn metabolic disorders were enrolled consecutively. The following clinical features were taken as clue for diagnosis of IEM: Lethargy, poor feeding, vomiting, irritability, altered sensorium, convulsions, coma, unconsciousness, apnoea, severe hypotonia, dysmorphism, congenital anomalies, hypoglycemia, heart failure, failure to thrive, inverted nipples, abnormal fat distribution, cardiomegaly, difficulty in respiration, jaundice, liver dysfunction, early onset cataracts, hepatosplenomegaly, renal, skeletal defects, abnormal body odour, bleeding diathesis. Newborns with

\footnotetext{
*Corresponding author: Kanij Fatema, Associate Professor, Department of Pediatric Neurology, BSMMU, Dhaka, Bangladesh, Tel: 0171-309-7751
}

Accepted: September 10, 2018; Published online: September 12, 2018

Citation: Rahman M, Fatema K, Shahidullah (2018) Incidence of Inborn Errors of Metabolism in Sick Neonates in a Tertiary Care Hospital in Developing Country. J Pediatr Neurol Neurosci 2(1):34-38

Copyright: (c) 2018 Rahman M, et al. This is an open-access article distributed under the terms of the Creative Commons Attribution License, which permits unrestricted use, distribution, and reproduction in any medium, provided the original author and source are credited. 
Citation: Rahman M, Fatema K, Shahidullah (2018) Incidence of Inborn Errors of Metabolism in Sick Neonates in a Tertiary Care Hospital in Developing Country. J Pediatr Neurol Neurosci 2(1):34-38

Table 1: Clinical characteristics of the sick newborns (N-50).

\begin{tabular}{|l|l|l|}
\hline Age of presentation & Frequency & $\%$ \\
\hline $1^{\text {st }}$ week & 21 & 42 \\
\hline $2^{\text {nd }}$ week & 15 & 30 \\
\hline $3^{\text {rd }}$ week & 3 & 6 \\
\hline $4^{\text {th }}$ week & 11 & 22 \\
\hline Sex of the studied patient & & \\
\hline Male & 26 & 52 \\
\hline Female & 24 & 48 \\
\hline Gestational age & & \\
\hline Preterm & 28 & 56 \\
\hline Full term & 22 & 44 \\
\hline Birth weight & & \\
\hline Low birth weight & 20 & 40 \\
\hline Normal & 19 & 38 \\
\hline Very low birth weight & 11 & 22 \\
\hline Consanguinity & & \\
\hline Absent & 35 \\
\hline Present & 15 & 70 \\
\hline
\end{tabular}

electrolyte imbalance, hypocalcemia, hypercalcemia, hypoglycemia, hyperglycemia, abnormal ammonia and lactate level, metabolic and respiratory acidosis/alkalosis which could not be explained by other causes were also included. Demographic characteristics, age at diagnosis, clinical and family history and parental consanguinity were also recorded.

The blood samples were collected on filter paper and sent to the laboratory, where the screening for the disorders of amino acids, organic acids and fatty acid metabolism were done by Tandem Mass Spectrometer. Tandem Mass Spectrometer is a computer-controlled device that separates and quantitates compounds from a single blood spot sample on filter paper by which metabolic disorders are detected. Ethical clearance has been taken from the Institutional review board.

\section{Results}

\section{Characteristics of the studied newborn}

Out of 50 clinically suspected sick newborns, 21 (42\%) presented during the first week of life and 15 (30\%) presented during the $2^{\text {nd }}$ week of life (Table 1). In other words, $36(72 \%)$ neonates presented during the first two weeks of life. Male and female ratio was 1.08:1. Twenty-eight (56\%) were preterm and $22(44 \%)$ were full term. Twenty (40\%) had low birth weight but $11(22 \%)$ had very low birth weight (birth weight below 1500 gm). History of consanguinity was present in 17 (34\%) cases (Table 1).

\section{Antenatal problems}

In $37(74 \%)$ cases, there was no history of antenatal problem while in $13(26 \%)$ cases there was antenatal problem. Diabetes mellitus (14\%), Fever (18\%), hyper-
Table 2: Incidence of Antenatal problem in the studied cases (N-50).

\begin{tabular}{|c|l|l|}
\hline Antenatal problem & Frequency & $\%$ \\
\hline Absent & 37 & 74 \\
\hline Present & 13 & 26 \\
\hline Types of Antenatal problem & & \\
\hline Fever & 9 & 18 \\
\hline Hypertension & 7 & 14 \\
\hline Diabetes mellitus & 7 & 14 \\
\hline Antepartum hemorrhage & 2 & 4 \\
\hline Hypothyroidism & 1 & 2 \\
\hline Bad obstetric history & & \\
\hline Sib death & 12 & 24 \\
\hline Abortion & 4 & 8 \\
\hline Intrauterine death & 2 & 4 \\
\hline
\end{tabular}

Table 3: Perinatal problem in the studied cases (N-50).

\begin{tabular}{|c|l|l|}
\hline Perinatal problem & Frequency & $\%$ \\
\hline Yes & 26 & 52 \\
\hline No & 24 & 48 \\
\hline PROM $^{*}$ & 8 & 16 \\
\hline Fever & 1 & 2 \\
\hline PNA $^{*}$ & 8 & 16 \\
\hline
\end{tabular}

"PROM- Premature rupture of Membrane; "PNA- Perinatal asphyxia.

Table 4: Neonatal Sickness in the studied cases (N-50).

\begin{tabular}{|c|l|l|}
\hline Pattern of sickness & Frequency & $\%$ \\
\hline Seizure & 19 & 38 \\
\hline Congenital heart disease & 2 & 4 \\
\hline Septicemia & 12 & 24 \\
\hline Jaundice & 17 & 34 \\
\hline Respiratory distress syndrome & 1 & 2 \\
\hline
\end{tabular}

tension (14\%) were the main antenatal problem. There was history of sibling death in $24 \%$ cases, history of abortion in $8 \%$ cases. Past history of intrauterine death was present in $4 \%$ cases (Table 2).

\section{Perinatal problems}

History of perinatal problems was found in $26(52 \%)$ cases. Perinatal asphyxia was present in $8(16 \%)$ cases (Table 3).

\section{Neonatal sickness pattern}

Nineteen (38\%) newborns had seizure and 17 (34\%) had jaundice, while $12(24 \%)$ neonates were septicemic (Table 4).

\section{Biochemical abnormalities}

Hyperammonaemia was the predominant biochemical abnormalities (42\%). Next common abnormalities were increased lactate (22\%) and hyponatraemia (16\%) (Table 5).

\section{Pattern of metabolic disorders}

Acetyl carnitine (C2) deficiency 38\%, octadecanoyl- 
Citation: Rahman M, Fatema K, Shahidullah (2018) Incidence of Inborn Errors of Metabolism in Sick Neonates in a Tertiary Care Hospital in Developing Country. J Pediatr Neurol Neurosci 2(1):34-38

Table 5: Biochemical abnormalities in the studied cases.

\begin{tabular}{|l|l|l|}
\hline Biochemical abnormality & Frequency & $\%$ \\
\hline Hypoglycemia & 4 & 8 \\
\hline Hyperammonemia & 21 & 42 \\
\hline Increased lactate & 11 & 22 \\
\hline Hyponatremia & 8 & 16 \\
\hline Hypernatremia & 2 & 4 \\
\hline Hypocalcemia & 5 & 10 \\
\hline Hypokalaemia & 2 & 4 \\
\hline Hypokalemia & 1 & 2 \\
\hline Acidosis & 3 & 6 \\
\hline Alkalosis & 2 & 4 \\
\hline
\end{tabular}

Table 6: Amino acids, Organic acids, Fatty acids Disorders (Tandem Mass Spectrometry).

\begin{tabular}{|c|c|c|c|}
\hline & Decreased Level & Frequency & $\%$ \\
\hline \multirow[t]{3}{*}{ Organic acid } & Acetylcarnitine (C2) & 19 & 38 \\
\hline & Free Carnitine (C0) & 1 & 2 \\
\hline & Propionylcarnitine (C3) & 1 & 2 \\
\hline \multirow[t]{5}{*}{ Fatty acid } & Octadecanoylcarnitine (C18) & 12 & 24 \\
\hline & Palmitoylcarnitine (C16) & 1 & 2 \\
\hline & Myristiylcarnitine (C14) & 1 & 2 \\
\hline & Total & 35 & 70 \\
\hline & Increased level & & \\
\hline \multirow[t]{4}{*}{ Amino acid } & Glycine & 7 & 14 \\
\hline & Leucine & 1 & 2 \\
\hline & Phenylalanine & 1 & 2 \\
\hline & Total & 9 & 18 \\
\hline Enzyme & Biotinidase deficiency & 2 & 4 \\
\hline
\end{tabular}

Table 7: Multiple abnormalities of Amino acids, Organic acids, Fatty acids Disorders (Tandem Mass Spectrometry).

\begin{tabular}{|l|l|l|}
\hline Type of multiple abnormalities & Frequency & $\%$ \\
\hline Decreased C2 + Increased Glycine & 2 & 4 \\
\hline Decreased C2 + Decreased C18 & 8 & 16 \\
\hline $\begin{array}{l}\text { Decreased C0 + Decreased C2 + } \\
\text { Decreased C18 }\end{array}$ & 1 & 2 \\
\hline Increased Glycine + Decreased C18 & 1 & 2 \\
\hline $\begin{array}{l}\text { Increased Glycine + Decreased C2 + } \\
\text { Decreased C18 }\end{array}$ & 1 & 2 \\
\hline $\begin{array}{l}\text { Decreased C16 + Increased Leucine + } \\
\text { Increased phenylalanine }\end{array}$ & 1 & 2 \\
\hline Decreased C2 + Decreased C13 & 1 & 2 \\
\hline Total & 15 & 30 \\
\hline
\end{tabular}

carnitine (C18) deficiency (24\%), biotinidase deficiency (4\%) (Table 6). However, in 30\% cases there were multiple biochemical abnormalities (Table 7).

Out of 50 cases, 32 cases (64\%) had abnormal TMS report. Ten types of abnormalities were found. There was overlapping of abnormalities (Table 7).

\section{Discussion}

Inborn errors of metabolism causing clinical manifestations in the neonatal period are usually severe and are often lethal if proper therapy is not promptly initiated. Clinical findings are usually non-specific and similar to those seen in infants with sepsis. An inborn error of metabolism should be considered in the differential diagnosis of a severely ill neonatal infant, and special studies should be undertaken if the index of suspicion is high. It has been shown that if detected early, complication in these disorders could be easily prevented with dietary restriction of the offending food constituent of metabolite [10].

The maximum amount of sick newborn presented at $1^{\text {st }}$ week, 20 (42\%) in number in this study. MH Hampe, et al. in their study found that most of the children were from 15 days to 2 months of age [11]. There was a slight male predominance (52\%) which is also observed in the literature, probably due to the occurrence of IEM with $\mathrm{X}$-linked recessive inheritance [12]. However, male female difference was not statistically significant.

We found 28 infants (56\%) of our study group was preterm whereas $40 \%$ and $22 \%$ were low birth weight and very low birth weight respectively. In one study done by Andressa Romao, et al. it has been stated that both gestational age and post birth chronological age significantly influenced the metabolic profile. Twenty-nine percent of infants at 23 to 26 weeks' gestational age had an abnormal metabolic profile compared with $17 \%$ of infants at 29 to 31 weeks' gestational age $(P<0.01)$ in their study [13].

Consanguinity was identified in $34 \%$ of neonates, but no family history of previously diagnosed metabolic disorder was identified. This number is relatively high in respect to related study. For example, in one study done in Brazil, the patients having consanguinity was 9.7\% whereas $6.9 \%$ of patients in Indian study. However, consanguinity was very high (86.9\%) in a study done in Libya where number of consanguineous marriages is very high $(48.4 \%)[14,15]$. Antenatal problems were identified in $26 \%$ of our patients like diabetes mellitus (14\%), fever $(18 \%)$, hypertension (14\%), antepartum hemorrhage (4\%) and hypothyroidism (2\%). Thus, even if there are adverse antenatal events, suspicion of IEM should not be discarded. There was history of sibling death in $24 \%$ cases, history of abortion in $8 \%$ cases. Past history of intrauterine death was in $4 \%$ cases. But in none of the cases evaluation of IEM was searched. This issue highlights the necessity of postmortem evaluation of every unusual mortality.

While searching for perinatal adversity of the study group, we found that 26 neonates (52\%) had some sorts of adversity. The perinatal problems were premature rupture of membrane (PROM) (16\%), fever (2\%) and history of delayed cry (Perinatal asphyxia) (16\%). The important clinical findings that caused the suspicion of IEM were, seizure $(38 \%)$, jaundice $(34 \%)$, septicemia $(24 \%)$, congenital heart disease (4\%) and respiratory distress (2\%). 
Citation: Rahman M, Fatema K, Shahidullah (2018) Incidence of Inborn Errors of Metabolism in Sick Neonates in a Tertiary Care Hospital in Developing Country. J Pediatr Neurol Neurosci 2(1):34-38

In this relation, it can be mentioned that in a study done in India the clinical features were poor feeding (4.3\%), lethargy (6.4\%), failure to thrive (4\%), seizures (10.6\%), delayed milestones $(6 \%)$, behavior disturbances $(1.7 \%)$, irritability $(2.8 \%)$, ataxia $(0.6 \%)$, abnormal muscle tone $(2.8 \%)$, attention deficit $(0.92 \%)$, coma $(1.07 \%)$, hepatomegaly $(1.53 \%)$, splenomegaly $(0.61 \%)$, metabolic acidosis $(7.2 \%)$, apnea $(2 \%)$, skeletal abnormalities $(0.92 \%)$, microcephaly (1.4\%), dysmorphic facial features $(2.2 \%)$ [16]. Thus, deterioration of neurological function acutely is a clue for IEM. In the studies of Sanseverino, et al. the acute neurological alterations caused the metabolic investigation of $47.8 \%$ of the patients and were present in all those who had a definite diagnosis of an IEM $[12,17]$.

Recognition and investigation of neonates with IEM is of utmost importance. Pediatricians and neonatologists play a significant role in identifying which infants should be investigated. Alternation of biochemical tests are important clue for suspecting metabolic diseases. Most common disorder in neonatal period are organic acid disorders that present with ketoacidosis and urea cycle defects characterized by hyperammonemia [18]. Our commonest finding was also hyperammonemia (42\%) and lactic acidosis (22\%). These finding coincide with similar study done by Mehmet, et al. where $29.4 \%$ neonates developed hypoglycemia and $25.5 \%$ developed lactic acidosis [19]. However, our other finding were hyponatremia, hypocalcemia, hypokalemia, hyperkalemia, acidosis and alkalosis.

Out of 50 sick neonates, $64 \%$ ( 32 cases) had abnormal TMS. We found 10 different types of IEM in our study. Till date more than 400 biochemically diverse IEM have been identified [20]. During the newborn period phenylketonuria, maple syrup urine disease, tyrosinemia, propionic academia, galactosemia and Zellweger syndrome were the frequently recorded IEM [21,22]. Our study showed consistency with the above study like we had one patient with propionic academia, 1 patient with PKU. However other patients showed acetyl carnitine deficiency in 19 infants (38\%), fatty acid disorder (14 patients), hyperglycinemia in 7 patients (14\%). We found one patient with biotinidase deficiency. As TMS was only done in this study thus we may have missed some cases as we did not perform GCMS and genetic study. In a related study done in same country by Mollah DH, et al. the most common IEM was biotinidase deficiency. Other disorders here were maple syrup urine disease, hyperammonemia-hyperornithinemia-hypercitrullinemia (HHH) syndrome, fatty acid oxidation disorder, carnitine transporter deficiency, arginase activity deficiency and methylmalonic academia [23].

In TMS in some cases we found multiple abnormalities which were nonconclusive. Fifteen (30\%) of our pa- tients showed multiple abnormalities. Additional investigations such as Gas Chromatography-Mass Spectroscopy (GC-MS), mitochondrial, comprehensive analysis of Mitochondrial genome with next generation sequencing (NGS), CSF lactate, CSF glycine, enzymatic study, MRI of brain could not be done in all cases as these needs sophisticated equipment's and are expensive.

\section{Conclusion}

Despite the limitation of the study, this study indicates the scope of IEM diagnosis in a developing country like Bangladesh. It will help to establish metabolic diagnosis in suspected cases of IEM and manage the cases early.

\section{References}

1. AE Garrod (1902) The incidence of alkaptonuria: A study in chemical individuality. The Lancet 13: 1616-1620.

2. R Christopher, BP Sankaran (2008) An insight into the biochemistry of inborn errors of metabolism for a clinical neurologist. Ann Ind Acad Neurol 11: 68-81.

3. Mak CM, Lee HC, Chan AY, et al. (2013) Inborn errors of metabolism and expanded newborn screening: Review and update. Crit Rev Clin Lab Sci 50: 142-162.

4. Ambani IM, Patel ZM, Dhareshwar SS, et al. (1984) Clinical biochemical and cytogenetic studies in mental retardation. Indian J Med Res 79: 384-387.

5. SA Latheef (2010) A database for inborn errors of metabolism in the Indian state of Andhra Pradesh. Bioinformation 4: $276-277$.

6. Aicardi J, Ogier H (1992) Metabolic diseases. In: Diseases of the Nervous System in Childhood. ( $1^{\text {st }}$ edn), Ed Aicardi J New York, Cambridge University Press, 379-517.

7. Chace DH, Millington DS, Terada N, et al. (1993) Rapid diagnosis of phenylketonuria by quantitative analysis for phenylalanine and tyrosine in neonatal blood spots by tandem mass spectrometry. Clin Chem 39: 66-71.

8. Chace DH, Hilman SL, Millington DS, et al. (1995) Rapid diagnosis of maple syrup urine disease in blood spots from newborns by tandem mass spectrometry. Clin Chem 41: 62-68.

9. Chace DH, Hillman SL, Millington DS, et al. (1996) Rapid diagnosis of homocystinuria and other hypermethionemias from newborns blood spots by tandem mass spectrometry. Clin Chem 42: 349-355.

10. Richard BS, Jenson HB. Kliegman RM (2000) Nelson Textbook of Pediatrics. (16th edn), Harcourt Asia, 343-344.

11. Hampe MH, Panaskar SN, Yadav AA, et al. (2017) Gas chromatography/mass spectrometry-based urine metabolome study in children for inborn errors of metabolism: An Indian experience. Clin Biochem 50: 121-126.

12. Amâncio FA, Scalco FB, Coelho CA (2007) Investigação diagnóstica de erros inatos do metabolismo em um hospital universitário. J Bras Patol Med Lab 43: 169-174.

13. A Romãoa, PEA Simonb, JEC Góesc, et al. (2017) Initial Clinical Presentation in Cases of Inborn Errors of Metabolism in a Reference Children's Hospital: Still A Diagnostic Challenge. Rev Paul Pediatr 35: 258-264. 
Citation: Rahman M, Fatema K, Shahidullah (2018) Incidence of Inborn Errors of Metabolism in Sick Neonates in a Tertiary Care Hospital in Developing Country. J Pediatr Neurol Neurosci 2(1):34-38

14. HA Obaidy (2013) Patterns of inborn errors of metabolism: A 12-year single-center hospital-based study in Libya. Qatar Med J 2: 57-65.

15. TB Omran, AA Wahab (2010) Genetic Disorders In Arab Populations: Qatar 60-65.

16. AN Rao, J Kavitha, M Koch, et al. (2009) Inborn errors of metabolism: Review and data from a tertiary care center. Indian J Clin Biochem 24: 215-222.

17. MTV Sanseverino, M Wajner, R Giugliani (2000) Application of a clinical and laboratory protocol for the investigation of inborn errors of metabolism among critically ill children. Jornal de Pediatria 76: 375-382.

18. DA Applegarth, JR Toone, RB Lowry (2000) Incidence of Inborn Errors of Metabolism in British Columbia, 19691996. Pediatrics 105: 1-6.
19. Gündüz M, Ünal S, Okur İ, et al. (2015) Neonates with inborn errors of metabolism: Spectrum and short-term outcomes at a tertiary care hospital. Turk J Pediatr 57: 45-52.

20. Martins AM (1999) Inborn errors of metabolism: A clinical overview. Sao Paulo Med J/Rev Paul Med 117: 251-265.

21. Couce ML, Castiñeiras DE, Bóveda MD, et al. (2011) Evaluation and long-term follow-up of infants with inborn errors of metabolism identified in an expanded screening programme. Mol Genet Metab 104: 470-475.

22. Kamate M, Chetal V, Kulgod V, et al. (2010) Profile of inborn errors of metabolism in a tertiary care centre PICU. Indian J Pediatr 77: 57-60.

23. DH Mollah, MM Rahman, KA Karim, et al. (2016) Pattern of Neurometabolic Disorders among Children Attending in Child Neurology Unit of a Tertiary Level Hospital of Bangladesh. Health Science 6: 36-41. 